\title{
Surgical Incision
}

National Cancer Institute

\section{Source}

National Cancer Institute. Surgical Incision. NCI Thesaurus. Code C15384.

An intentional cut made to an individual's body with the intent of performing a diagnostic or therapeutic intervention. 